\title{
Attentional strategic control over nonlexical and lexical processing in written spelling to dictation in adults
}

\author{
PATRICK BONIN, SANDRA COLLAY, MICHEL FAYOL, and ALAIN MÉOT \\ CNRS and Université Blaise Pascal, Clermont-Ferrand, France
}

\begin{abstract}
We conducted four experiments to investigate whether adults can exert attentional strategic control over nonlexical and lexical processing in written spelling to dictation. In Experiment 1, regular and irregular words were produced either in a nonword context (regular and irregular nonwords) or in a word context (high-frequency regular and irregular words), whereas in Experiment 2, the same set of words was produced either in a regular nonword or in an irregular low-frequency word context. Experiment 3 was a replication of Experiment 2 but with increased manipulation of the context. In Experiment 4, participants had to produce either under time pressure or in response to standard written spelling instructions. Regularity effects were found in all the experiments, but their size was not reliably affected by manipulations intended to increase or decrease reliance on nonlexical processing. More particularly, the results from Experiment 4 show that adults can speed up the initialization of their writing responses to a substantial degree without altering regularity effects on either latencies or spelling errors. Our findings suggest that, although adults are able to generate an internal deadline criterion of when to initialize the writing responses, nonlexical processing is a mandatory process that is not subject to attentional strategic control in written spelling to dictation.
\end{abstract}

How do adults write down isolated words from their auditory presentation? So far, little research has been devoted to the investigation of written spelling to dictation in real time in normals. Indeed, compared with research on reading, research on spelling in adults has not given rise to the construction of theories of comparable breadth and depth (Houghton \& Zorzi, 2003).

The spelling-to-dictation task has been framed within the dual-route view. According to this view, two routes can be used to derive orthography from an auditory string: a lexical and a nonlexical route. The lexical route delivers the spelling of known words by retrieving lexical knowledge, whereas the nonlexical route uses subword knowledge to derive the spelling of unknown words and nonwords. Indeed, the core idea of the dual-route view is that knowledge of sound-to-spelling mappings is separately represented from knowledge of the orthography of individual words. Traditionally, the dual-route view of spelling to dictation has been framed within the symbolic approach. However, recently a dual-route connectionist model of spelling to dictation has been elaborated (Houghton \& Zorzi, 2003). As in reading aloud, connectionist models have been proposed for spelling to dictation (e.g., Brown \& Loosemore, 1994; Olson \& Caramazza, 1994). How-

\footnotetext{
We thank Jay Rueckl, Debra Jared, Michael Cortese, and an anonymous reviewer for very constructive reviews. Correspondence concerning this article should be addressed to P. Bonin, Laboratoire de Psychologie Sociale et Cognitive (LAPSCO), Université Blaise Pascal, 34 avenue Carnot, 63037 Clermont-Ferrand, France (e-mail: patrick.bonin@ srvpsy.univ-bpclermont.fr).
}

ever, in contrast to reading aloud, where the connectionist view is fully developed and is proposed as a challenging alternative (e.g., Plaut, McClelland, Seidenberg, \& Patterson, 1996; Seidenberg \& McClelland, 1989; Zevin \& Seidenberg, 2002), this approach is not fully developed in the field of spelling to dictation, since researchers have tended to focus on the symbolic dual-route view. Thus, the dominant view of spelling to dictation is the symbolic dual-route view (Rapp, Epstein, \& Tainturier, 2002). In light of this observation, we will concentrate on this particular view in the remainder of the article.

The dual-route view of spelling to dictation is supported by various lines of argument (Barry, 1994). First of all, the fact that adults can, without much difficulty, spell nonwords or new words, and sometimes produce phonologically plausible spelling errors on words is generally taken to argue for the existence of a nonlexical route. Also, memorizing individual orthographic patterns seems crucial for the accurate spelling of many irregular words. Second, the analyses of spelling errors exhibited by certain patients are consistent with the involvement of sublexical as well as lexical knowledge. In effect, some patients have been found to be able to produce nonwords while performing poorly on words, and more particularly, irregular words (e.g., Baxter \& Warrington, 1987; Beauvois \& Dérouesné, 1981; Behrmann \& Bub, 1992; Goodman \& Caramazza, 1986; Sanders \& Caramazza, 1990), while the opposite observation has been reported in other patients (e.g., Baxter \& Warrington, 1985; Bub \& Kertesz, 1982; Shallice, 1981). This double dissociation has been taken as strong support for the existence of 
two different processing pathways in spelling to dictation (Barry, 1994). Finally, evidence from normal participants who were asked to spell words and nonwords is consistent with this idea of separate processing pathways (e.g., Perry \& Ziegler, 2004).

Given that the nonlexical route operates by applying knowledge of sound-to-spelling mappings, one issue is to specify the size of the sound-spelling correspondences used. Traditionally, phoneme-grapheme units have been proposed (Goodman \& Caramazza, 1986; Tainturier \& Rapp, 2000). Recent evidence from spelling-to-dictation experiments involving words and nonwords in adults does indeed suggest that both phoneme-grapheme and larger sized subsyllabic sound-spelling mappings make independent contributions. Perry and Ziegler (2004) examined the spelling of nonwords in situations where the two most likely potential spellings were manipulated along the dimension of interest (e.g., phoneme-grapheme correspondences). The logic behind this is that nonword spelling responses should be influenced if the dimension of interest is important. Perry and Ziegler (2004) and Perry, Ziegler, and Coltheart (2002) found that the effects of phoneme-grapheme mappings seem stronger and more reliable than those of larger sound-spelling units. For instance, Perry et al. examined the effects of rime-body consistency and of phoneme-grapheme contingency in a large-scale nonword spelling task. Correlational analyses revealed that, with rime-body consistency partialed out, phoneme-grapheme contingency correlated reliably with spelling responses. Also, rimebody consistency correlated reliably with spelling responses, with phoneme-grapheme contingency partialed out. Importantly, the effect of phoneme-grapheme contingency was much stronger than the effect of rime-body consistency. Thus, Perry et al.'s study suggests that people typically spell nonwords by using phoneme-grapheme correspondences rather than larger rime-body correspondences. In spelling, there is no controversy about whether the nonlexical route involves a system of rule-based correspondences or one of learned correspondences reflecting degrees of phonology-to-orthography (PO) consistency, in contrast to a debate on the connection with word reading (Coltheart, Rastle, Perry, Langdon, \& Ziegler, 2001; Jared, 2002; Zorzi, 2000; Zorzi, Houghton, \& Butterworth, 1998). PO consistency is a notion that captures a statistical relationship between sublexical phonological and orthographic units (Peereman \& Content, 1999): An inconsistent word is one for which the number of alternative spellings for a given phonological unit (e.g., onset, vowel, rime) is relatively high, whereas a consistent word is one for which the mappings between phonological and orthographic units are more systematic. PO consistency effects have been found on both written spelling-to-dictation latencies and spelling errors in adults (e.g., Bonin \& Méot, 2002; Bonin, Peereman, \& Fayol, 2001; Peereman, Content, \& Bonin, 1998), and the effects are stronger on low-frequency words than on high-frequency words (Bonin \& Méot, 2002). In contrast to consistency, regu- larity is a categorical notion. Regular words are those whose correspondences at the phoneme-grapheme level follow the most often represented renderings. Irregular words are those that contain at least one very low-frequency phoneme-grapheme relationship. ${ }^{1}$

Because evidence suggests that adults rely more on phoneme-grapheme units than on larger units when spelling (Perry \& Ziegler, 2004), in keeping with the traditional dual-route view, and in line with other authors (e.g., Rapp et al., 2002), we will assume that the nonlexical procedure operates at least on phoneme-grapheme mappings. In the experiments reported below, the critical set of words differed both on consistency defined essentially in terms of vowel and rime-body correspondences and phoneme-grapheme correspondences. Thus, the words were either consistent/regular or inconsistent/irregular. For the sake of simplicity, we will henceforth use the terms regular and irregular. However, we will not take a stance as to whether the nonlexical procedure is better described as operating upon rule-based correspondences or learned correspondences reflecting degrees of PO consistency.

Different versions of the dual-route view in spelling have been put forward and assign different roles to each of the two routes. At present, a growing body of evidence favors the hypothesis that both routes are involved and provide their output at a common processing level. More precisely, in the recent model of spelling to dictation put forward by Rapp et al. (2002), the two routes provide their computations at the level of individual graphemes (see Figure 1). The lexical route is assumed to be generally faster than the nonlexical route. When words are high in frequency in the language, the lexical route provides its output at the grapheme level sooner than does the nonlexical route. For low-frequency words, because their retrieval from the mental lexicon takes more time, the nonlexical route can provide its computation at the grapheme level simultaneously. In this latter case, the two routes give the same output when the word is regular. If the word is irregular, the two routes will produce conflicting responses because the lexical route provides the correct response, while the nonlexical route provides an erroneous one: a phonologically plausible spelling error. We assume that the regularity effect on onset latency - a latency cost for irregular words, as compared with regular words - is because the resolution of the conflict takes some time. This version of the dual view in spelling is supported by the observation of an interaction between word frequency and regularity in neurologically intact participants (e.g., Bonin \& Méot, 2002; Kreiner, 1996), as well as in brain-damaged patients (e.g., Rapp et al., 2002). The interaction primarily takes the form of a regularity cost for low-frequency words.

A shared assumption among dual-route theorists is that the two routes differ in their processing characteristics. As discussed above, the nonlexical route is slower than the lexical route. Also, the former is less automatized than the latter. A reasonable assumption is thus that the nonlexical route might be under strategic control. Its 


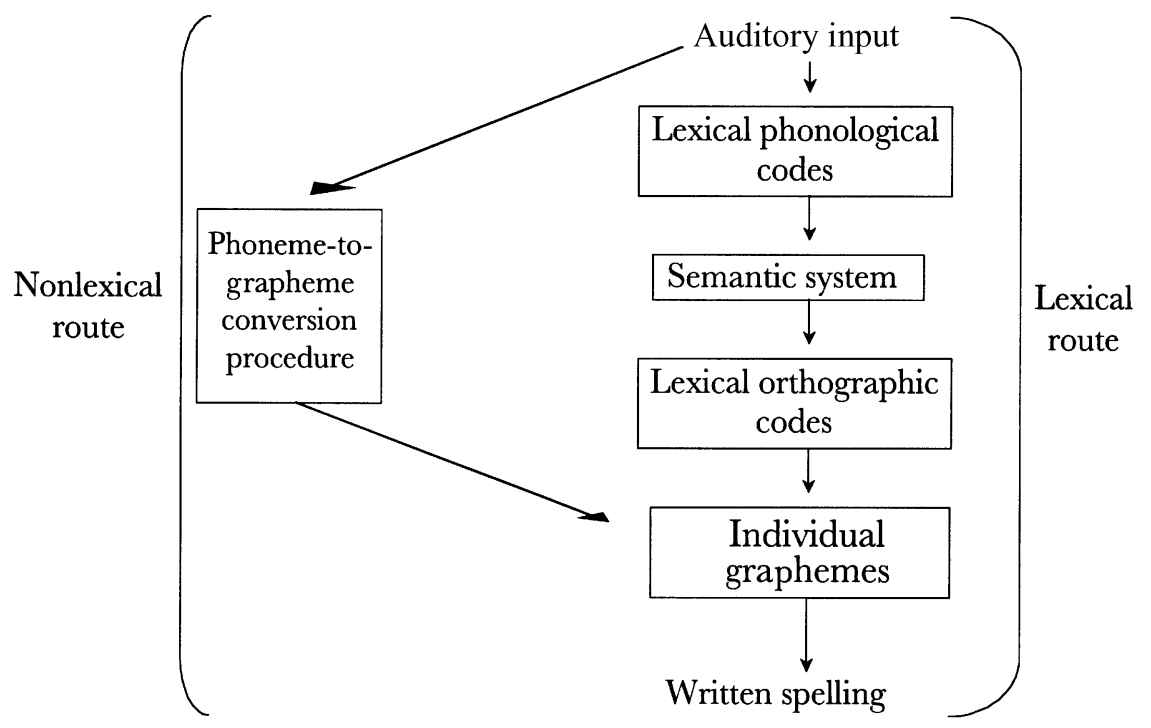

Figure 1. Dual-route model of written spelling to dictation (adapted from Rapp, Epstein, \& Tainturier, 2002).

involvement in spelling words might be emphasized or deemphasized under certain conditions. Indeed, the aim of the present study is to find out whether adults can have strategic control over nonlexical processing in written spelling to dictation, an issue that has not so far been investigated in written spelling to dictation. The situation is in sharp contrast with the word-reading domain, in which this issue occupies a prominent position and has been a focus of debate, as we will explain below. Indeed, an ongoing controversy is whether readers can truly have strategic control over the type of processing they engage in when reading words.

The question of strategic control in word reading has generally been examined within the dual-route framework (e.g., Paap \& Noel, 1991). As already stated, we have adopted this approach as far as written spelling to dictation is concerned. One method that has been used to investigate whether readers can have strategic control over the processing pathways in reading has been to present critical items in different stimulus contextsnamely, by using filler items. Because the lexical route is thought to be more automatized than the nonlexical route, it may be hypothesized that the latter route can be under strategic control (Kinoshita \& Lupker, 2002). Therefore, the critical manipulation is to vary the level of use of nonlexical processing by using filler items that direct attention, to a greater or lesser extent, to nonlexical processing. According to the dual-route view, nonwords can be read aloud correctly only with the use of the nonlexical route, whereas low-frequency irregular words can be read aloud correctly only by retrieving their stored pronunciation within the lexical route. Therefore, the inclusion of a large number of nonwords in the list of critical items should tend to direct attention to nonlexical processing, whereas the inclusion of many irregular words should direct attention to lexical processing, and only to a lesser extent to nonlexical processing. Certain findings are consistent with the hypothesis that readers can have strategic control over the nonlexical pathway. For instance, Monsell, Patterson, Graham, Hughes, and Milroy (1992) found that high-frequency exception words ${ }^{2}$ were named more slowly when nonwords were included in the stimulus list. Assuming that readers can have control over the type of processing, this finding suggests that they can emphasize nonlexical processing when the stimulus environment is made up of many stimuli (nonwords) that cannot be processed via the lexical pathway. Of particular interest are the manipulations that have been used to test whether the size of the effects, which are assumed to reflect the involvement of either the lexical or the nonlexical route, are affected by the nature of the fillers. For instance, associative priming effects, which are assumed to be due to processing within the lexical route, disappear in Italian when nonwords are used as fillers in the list (Tabossi \& Laghi, 1992). Also, word frequency effects, which are thought to reflect the involvement of the lexical route, diminish when nonwords are used as fillers (Baluch \& Besner, 1991) or in low-frequency regular word filler environments when compared with low-frequency exception filler environments (Kinoshita \& Lupker, 2002). However, one well-established effect that has rarely been found to be affected by the composition of the stimuli in the list is the regularity effect (Coltheart \& Rastle, 1994; Jared, 1997; Kinoshita \& Lupker, 2002; Waters \& Seidenberg, 1985; Woollams \& Kinoshita, 1997). Indeed, only the Zevin and Balota (2000) study has provided evidence of an alteration of the regularity effect in reading aloud. In this study, a priming manipulation was used. Participants saw five primes prior to naming a target, which was either a nonword or an exception word, in order to emphasize either nonlexical or lexical processing. In line with the hypothesis of attentional strategic 
control, the regularity effect on targets increased following nonword primes (but see Kinoshita \& Lupker, 2003).

An alternative account of list composition effects in word reading is referred to as the flexible time-criterion account (Chateau \& Lupker, 2003; Kinoshita \& Lupker, 2003; Lupker, Brown, \& Colombo, 1997; Taylor \& Lupker, 2001). According to this hypothesis, readers do not always initiate articulation as soon as they are ready to do so. The position of the time criterion is set on the basis of the relative difficulty of the items in the list. In lists consisting of only fast stimuli (words), the naming latencies would be faster for the critical set of words than when the same set of words is mixed with a list of pure slow stimuli (nonwords). According to Taylor and Lupker, the decision about when to initiate the articulatory processes is driven by some combination of quality of phonological representations and time criteria. Recently, Kinoshita and Lupker (2002) conducted two word reading experiments in order to shed light on the issue of whether filler type effects are better accounted for by a strategic attentional control pathway hypothesis or by a time-criterion hypothesis. In both experiments, lowfrequency exception words were used as one filler type. In addition, in their Experiment 1, nonword fillers were also included, whereas in their Experiment 2, lowfrequency regular word fillers were used. In both experiments, the size of the regularity effect was unaffected by the filler type composition. However, when compared with the context involving low-frequency exception fillers, the size of the frequency effect was reduced in the context of low-frequency regular word fillers but not in the context of nonword fillers. The authors argued that their findings were better explained by a time-criterion account than by an attentional control pathways account. Indeed, as they argued, if participants were truly producing a decreased frequency effect through the more extensive use of nonlexical processing in the regular word filler condition, the size of the regularity effect should have increased. Moreover, the absence of a modulation of the size of the frequency effect in a context of nonword fillers is puzzling, given that nonwords are supposed to increase reliance on the nonlexical route. The use of nonword fillers should therefore have resulted in the greatest reduction in the size of the frequency effect. Even the Zevin and Balota (2000) study described above, which has provided evidence for modulation of the regularity effect, has been challenged. Using a priming manipulation similar to Zevin and Balota's, Kinoshita and Lupker (2003) did not find that the size of the regularity effect was affected by prime type.

Turning now to written spelling to dictation, it is obvious that the same line of reasoning applies as in connection with word reading. However, we are not aware of any study to date that has investigated whether spellers can exert control over nonlexical processing. Although there is, at present, no unambiguous evidence that the regularity effect in reading aloud can be altered by a filler type manipulation (Chateau \& Lupker, 2003), we investigated this issue in written spelling to dictation because reading is a more frequently practiced skill than written spelling to dictation. Therefore, strategic control over nonlexical processing might be possible in written spelling to dictation and quite impossible (or to a much lesser extent) in reading aloud due to a difference in the level of automatization of the underlying processes. Given that in French there is a high degree of inconsistency between phonological and orthographic units (Peereman \& Content, 1999), it would be advantageous for spellers to have control over the nonlexical pathway in order to reduce spelling errors and increase the speed of initialization of written spelling when prompted by the filler environment. If anything, the spelling-to-dictation task can be seen as another opportunity to test whether nonlexical processing can be modulated by list composition. The first two experiments were conducted in order to investigate whether adults can deemphasize nonlexical processing in written spelling to dictation by manipulating list composition. The critical words in the experiments took the form of regular/consistent and irregular/inconsistent words matched for word frequency (and other relevant variables; see the Stimuli section of Experiment 1). The regularity effect was used as an index of nonlexical processing. In Experiment 1, words were produced either in a nonword context (regular and irregular ${ }^{3}$ ) or in a word context (high-frequency regular and irregular words). In Experiment 2, a within-subjects design was used in which participants had to write down words mixed with either regular nonwords or low-frequency irregular words. If adults are able to adjust their attentional control over the lexical and nonlexical routes in written spelling to dictation, we should observe that regularity effects are more sizable in a nonword context than in a word context.

\section{EXPERIMENT 1}

In order to produce a greater emphasis on nonlexical processing in written spelling to dictation, we asked some of the participants to write down regular and irregular words in a nonword context made up of regular and irregular nonwords. According to the dual-route view of spelling to dictation, nonwords can only be produced via the nonlexical route, whereas words can be produced via both routes. Therefore, a nonword context should have the consequence of increasing the likelihood of participants using the nonlexical route for spelling words. As far as high-frequency words are concerned, the dual-route view holds that they are produced by retrieving their spelling directly from the orthographic lexicon. The use of high-frequency words as a context for producing the critical set of words should therefore reduce reliance on nonlexical processing. Because the regularity effect is thought to reflect the involvement of nonlexical processing, according to the attentional strategic control hypothesis, a greater emphasis on nonlexical processing should increase the regularity effect (on both latencies and errors). Therefore, we predicted that the size of the reg- 
ularity effect should be larger when the critical words are produced in a nonword context than when they are produced in a word context. According to the time-criterion account, a list composition effect on the written latencies for the experimental words is expected when the filler type latencies differ. However, no reliable alteration of the size of the regularity effect is expected since context manipulation has no impact on the nature of the processing (lexical vs. nonlexical processing).

\section{Method}

Participants. The participants were 40 psychology students at Blaise Pascal University. All were native speakers of French and had normal or corrected-to-normal vision and no known hearing deficit.

Stimuli. The critical stimuli consisted of 38 words: 19 regular/ consistent words and 19 irregular/inconsistent words. PO consistency refers to the variability of the orthographic codes that can be assigned to a specific phonological unit (onset, vowel, rime, etc.). The degree of consistency of a correspondence is estimated as the proportion of words in which the phonological unit occurs with a particular orthographic rendering relative to the total number of words that include the phonological unit. The consistency scoreswhich vary from perfectly inconsistent $(0.00)$ to perfectly consistent (1.00) - were taken from the LEXOP database (Peereman \& Content, 1999). In LEXOP, consistency scores are estimated for all possible units of segmentation including onset $(\mathrm{C} 1)$, vowel (V), coda (C2), and rime (final vowel-consonant [VC]) units. As shown in Table 1, most of the inconsistencies occurred on the vowel, coda and rime units. Words were matched on onset consistency.

Regular words are words whose correspondences at the phonemegrapheme level correspond to the most often represented renderings, and irregular words are those which contain at least one very low-frequency phoneme-grapheme relationship. LEXOP also provides, for each word, the consistency score for the least consistent phoneme-grapheme (PG) correspondences. As shown in Table 1, the consistent words were regular and the inconsistent words were irregular. For the sake of simplicity, we will refer to the experimental words as regular versus irregular words.

The words were matched on age of acquisition (AoA) values that were taken from Alario and Ferrand (1999) and from Bonin, Peereman, Malardier, Méot, and Chalard (2003), who asked adults to estimate the age at which they thought they had learned each of the words in either their spoken or written form, using a 5-point scale $(1=$ learned at $0-3$ years and $5=$ learned at $12+$ years, with 3 -year age bands in between). The regular and irregular words were matched on BRULEX frequency (Content, Mousty, \& Radeau, 1990), on FRANTEXT frequency (taken from LEXIQUE: New, Pallier, Ferrand, \& Matos, 2001) and on subjective frequency estimates taken from the Bonin, Méot, et al. (2003) normative study. The objective frequency values are given per million words. The subjective frequency of the words was evaluated on a 5-point scale (with $1=$ unknown word and $5=$ very frequently used in the spoken or in the written language). When compared with the words used in a large-scale spelling-to-dictation study (Bonin \& Méot, 2002 ), the words used in the present study were of medium objective word frequency (between the 4th and 6th decile).

The two sets of words were also matched for length in terms of number of letters, syllables, acoustic duration (full duration and from the uniqueness point) but not on number of phonemes or on the uniqueness point, the latter corresponding to the point at which the initial sequence of phonemes is particular to that word and no other (Marcus \& Frauenfelder, 1985). However, the latter two variables run counter to the direction of the regularity effect. The number of phonological neighbors was also controlled for, as were bigram frequency and diphone frequency. Bigram frequency values were taken from Content and Radeau (1988), and diphone frequencies were computed from the BRULEX database (Content et al.,

Table 1

Statistical Characteristics of the Experimental Words Used in Experiments 1, 2, 3, and 4

\begin{tabular}{|c|c|c|c|}
\hline & Irregular & Regular & $p$ values \\
\hline Concreteness & 4.51 & 4.65 & n.s. \\
\hline Emotional valence & 3.21 & 3.22 & n.s. \\
\hline Subjective frequency & 3.06 & 3.18 & n.s. \\
\hline Imageability & 4.12 & 4.34 & n.s. \\
\hline Concept familiarity & 3.13 & 2.89 & n.s. \\
\hline AoA (rated) & 2.55 & 2.41 & n.s. \\
\hline Brulex frequency $(\log )$ & $18.42(1.04)$ & $26.25(1.08)$ & n.s. (n.s.) \\
\hline Frantext frequency $(\log )$ & $11.71(.92)$ & $19.95(1.03)$ & n.s. (n.s.) \\
\hline $\mathrm{Nb}$ of letters & 4.89 & 5.21 & n.s. \\
\hline $\mathrm{Nb}$ of phonemes & 3.16 & 3.74 & $=.022$ \\
\hline $\mathrm{Nb}$ of syllables & 1.05 & 1.05 & n.s. \\
\hline Uniqueness point & 3.95 & 4.42 & $=.032$ \\
\hline Acoustic duration (msec) & 688.54 & 693.46 & n.s. \\
\hline Acoustic duration from UP (msec) & 634.77 & 669.02 & n.s. \\
\hline Diphone frequency $(\log )$ & $477.95(2.55)$ & $411.06(2.50)$ & n.s. \\
\hline No. of phonological neighbors & 9.63 & 8.42 & n.s. \\
\hline Bigram frequency (token)* & $797.80(2.75)$ & $1,040.5(2.92)$ & n.s. \\
\hline Bigram frequency (type)* & $796.17(2.79)$ & $920(2.92)$ & n.s. \\
\hline Onset (C1) consistency † & $.99(.90)$ & $.97(.97)$ & n.s. (n.s.) \\
\hline Vowel (V) consistency $\dagger$ & $.45(.43)$ & $.92(.99)$ & $<.0001(<.0001)$ \\
\hline Coda (C2) consistency $\dagger$ & $.53(.58)$ & $.85(.89)$ & $<.002(<.02)$ \\
\hline $\mathrm{C} 1 \mathrm{~V}$ consistency $\dagger$ & $.61(.57)$ & $.90(.89)$ & $<.002(<.01)$ \\
\hline VC2 consistency† & $.34(.29)$ & $.91(.97)$ & $<.0001(.0001)$ \\
\hline $\mathrm{PO} \mathrm{L} \uparrow$ & .11 & .74 & .0001 \\
\hline
\end{tabular}

Note-PO L, phonology-to-orthography consistency of the least phoneme-grapheme association. *From Content and Radeau (1988). †Values by type (by token in parentheses) as given by LEXOP (Peereman \& Content, 1999). 
1990). The number of phonological neighbors was taken from Peereman and Content (1999).

We took care to match the regular and irregular words on variables that are assumed to index semantic representations: Imageability, conceptual familiarity, and emotional valence (Bonin, Méot, et al., 2003; Cortese, Simpson, \& Woolsey, 1997; Plaut \& Shallice, 1993; Strain \& Herdman, 1999; Strain, Patterson, \& Seidenberg, 1995, 2002; van Hell \& de Groot, 1998). Measures of rated conceptual familiarity (i.e., the rated familiarity of the concept represented by the word's referent) were taken from Alario and Ferrand (1999), who used a 5 -point scale $(1=a$ very unfamiliar concept and $5=a$ very familiar concept). Measures of imageability (i.e., the ease with which a word arouses a mental image) were taken from Bonin, Méot, et al. who used a 5-point scale $(1=$ not easily imageable, $5=$ very easily imageable). Also, measures of emotional valence were taken from Bonin, Méot, et al., who also used a 5-point scale (5 = very positive feeling and 1 = very bad feeling).

The statistical characteristics of the experimental words are given in Table 1, and a list of the words is given in the Appendix.

The filler items were 52 nonwords (half regular and half irregular; the consistency scores on the PG correspondences were 74.78 and 52.59, respectively) and 26 high-frequency regular and 26 irregular words (the consistency scores on the rime unit were .89 and .18 , respectively, whereas on the PG units they were 70.22 and 54.73 , respectively), thus giving $58 \%$ of filler items, a ratio that is consistent with similar studies in the word reading domain (e.g., Chateau \& Lupker, 2003: ratio of fillers $=50 \%$; Kinoshita $\&$ Lupker, 2002: 50\%). The regular and irregular word fillers were matched on word frequency (97 vs. 110 per million), AoA (2.09 vs. 2.00), and acoustic duration (962 vs. $862 \mathrm{msec}$ ).

Apparatus. The experiment was run using PsyScope Version 1.2 (Cohen, MacWhinney, Flatt, \& Provost, 1993) on an Apple PowerMac computer. A graphic tablet (WACOM tablet) and a contact pen (Intuos2 Ink pen XP-110) were used to record written latencies. The computer controlled presentation of the words and recorded the naming latencies to the nearest millisecond. Sony MDR-301LP headphones were used to present the stimuli.

Procedure. All the participants were tested individually in sessions that lasted about $20 \mathrm{~min}$. The experimental session started with practice trials. The participants produced both regular and irregular words in either a word or a nonword context. They were randomly assigned to the two modalities of the context factor (nonwords vs. high-frequency words).

Each trial began with a visual ready signal $\left(^{*}\right)$ presented for $1,000 \mathrm{msec}$ at the center of the computer screen. It was followed, $200 \mathrm{msec}$ later, by the auditory stimulus presented through the headphones. The intertrial interval was $5 \mathrm{sec}$. The participants were required to write down the stimulus as fast as possible on the graphic tablet using the contact pen. They were told to write down a cross when the stimulus was not identified. After responding, the participants were instructed to concentrate on the center of the screen. The computer recorded the time that elapsed between the onset of the auditory word and the contact of the pen with the graphic tablet. The participants in the nonword filler condition were told that they would hear some nonwords which they had to write down, using the first spelling that came to mind.

Design. Word type (regular vs. irregular) was a within-subjects factor on participants and a between-subjects factor on items. List composition (nonwords vs. high-frequency words) was a betweensubjects factor on participants and a within-subjects factor on items.

\section{Results}

Observations were discarded from the latency analyses when a technical problem occurred $(0.26 \%)$, a word was not identified (and a cross was written instead; $0.13 \%$ ), was crossed out $(0.26 \%)$, or was misspelled $(4.8 \%)$. Moreover, written latencies longer than two standard deviations above the participant and item means were excluded from the latency analyses (1.97\% of the data). Overall, $7.42 \%$ of the data were discarded.

Analyses of variance were performed on the participant means $\left(F_{1}\right)$ and on the item means $\left(F_{2}\right)$. Analyses were performed on written latencies and on errors.

As far as the errors are concerned, three different kinds of analyses were conducted: (1) All error types included, that is to say, all trials that were excluded from the latency analyses as described at the beginning of the Results section; (2) phonologically plausible (PP), plus nonphonologically plausible (NPP) spelling errors; and (3) PP spelling errors only.

Mean written spelling latencies, the standard deviations of these means, and error rates are presented in Table 2.

Latencies. The regularity effect was reliable on both participants and items $\left[F_{1}(1,38)=53.82, M S_{\mathrm{e}}=2,002.14\right.$, $p<.001 ; F_{2}(1,36)=7.116, M S_{\mathrm{e}}=125,778.996, p<$ $.05]$. Experimental words were produced faster in a word context than in a nonword context, although the effect was significant only in the by-items analysis $\left[F_{1}<1\right.$; $\left.F_{2}(1,36)=34.033, M S_{\mathrm{e}}=3,122.654, p<.001\right]$. The interaction effect between regularity and list composition was not reliable $\left[F_{1}<1 ; F_{2}(1,36)=1.91\right]$.

All errors. Irregular words yielded more errors than did regular words $\left[F_{1}(1,38)=28.07, M S_{\mathrm{e}}=.003597\right.$, $\left.p<.001 ; F_{2}(1,36)=6.886, M S_{\mathrm{e}}=.013929, p<.05\right]$. The effect of list composition was significant only in the by-items analysis $\left[F_{1}(1,38)=3.46, p=.071 ; F_{2}(1,36)=\right.$ $\left.11.08, M S_{\mathrm{e}}=.002007, p<.01\right]$. The interaction effect

Table 2

Mean Written Spelling Latencies (in Milliseconds), Standard Deviations of the Means, and Error Rates (in Percentages) as a Function of Phonology-to-Orthography Regularity and List Composition in Experiment 1

\begin{tabular}{|c|c|c|c|c|c|c|c|c|}
\hline & \multicolumn{4}{|c|}{ Word Context } & \multicolumn{4}{|c|}{ Nonword Context } \\
\hline & \multicolumn{2}{|c|}{ Regular } & \multicolumn{2}{|c|}{ Irregular } & \multicolumn{2}{|c|}{ Regular } & \multicolumn{2}{|c|}{ Irregular } \\
\hline & $M$ & $S D$ & $M$ & $S D$ & $M$ & $S D$ & $M$ & $S D$ \\
\hline Written latency & 935 & 206 & 1,003 & 235 & 997 & 224 & 1,076 & 255 \\
\hline All E & \multicolumn{2}{|c|}{2.30} & \multicolumn{2}{|c|}{8.90} & \multicolumn{2}{|c|}{5.30} & \multicolumn{2}{|c|}{13} \\
\hline NPP and PP & \multicolumn{2}{|c|}{1.05} & \multicolumn{2}{|c|}{7.37} & \multicolumn{2}{|c|}{1.84} & \multicolumn{2}{|c|}{8.95} \\
\hline
\end{tabular}

Note-All E, all errors included; NPP and PP, nonphonological and phonological spelling errors included. 
between regularity and list composition was not significant $\left(F_{\mathrm{S}}<1\right)$.

PP and NPP spelling errors. The regularity effect was significant on both participants and items $\left[F_{1}(1,38)=\right.$ $31.78, M S_{\mathrm{e}}=.002834, p<.01 ; F_{2}(1,36)=6.58, M S_{\mathrm{e}}=$ $.012997, p<.05]$. Neither the main effect of list composition $\left[F_{1}(1,38)=1.49 ; F_{2}(1,36)=1.27, M S_{\mathrm{e}}=.002105\right]$ nor the interaction effect between list composition and regularity was significant $(F \mathbf{s}<1)$. Exactly the same pattern of results was found for PP spelling errors.

Filler items (words and nonwords). The same kinds of analyses were performed on the latencies and on the errors corresponding to the word and nonword fillers. As far as nonword fillers are concerned, a response was considered an error whenever a given nonword was produced in a nonphonologically plausible manner.

On the latency analysis, the main effect of regularity was significant $\left[F_{1}(1,38)=22.26, M S_{\mathrm{e}}=8,126.38, p<\right.$ $\left..01 ; F_{2}(1,99)=15.85, M S_{\mathrm{e}}=15,101.83, p<.01\right]$. Words were produced faster than nonwords $\left[F_{1}(1,38)=8.28\right.$, $M S_{\mathrm{e}}=8,126.38, p<.01 ; F_{2}(1,99)=256.27, M S_{\mathrm{e}}=$ $15,101.83, p<.01]$. Also, the interaction effect between type of fillers and regularity was significant $\left[F_{1}(1,38)=\right.$ $8.28, M S_{\mathrm{e}}=8,126.38, p<.01 ; F_{2}(1,99)=6.07, M S_{\mathrm{e}}=$ $15,101.83, p<.05]$. The interaction was such that the regularity effect was larger on nonwords (consistent: $1,185 \mathrm{msec}$, inconsistent: $1,338 \mathrm{msec}$ ) than on words (consistent: $852 \mathrm{msec}$, inconsistent: $889 \mathrm{msec}$ ). The regularity effect was not significant on errors (both $F \mathrm{~s}<1$ ). There were more errors with nonwords than with words $\left[F_{1}(1,38)=6.92, M S_{\mathrm{e}}=.008756, p<.01 ; F_{2}(1,99)=\right.$ $\left.7.45, M S_{\mathrm{e}}=0.008756, p=.007\right]$. The interaction effect between list composition and regularity was not significant $\left[F_{1}(1,38)=3.42, p=.072 ; F_{2}(1,99)=1.36\right]$.

\section{Discussion}

A regularity effect was found on both the latencies and errors. The effect of list composition was reliably observed on the latencies in the by-items analysis only. More precisely, irregular and regular experimental words were produced faster when the fillers were words than when they were nonwords. On errors, the effect of filler type was not significant. Importantly, the regularity effect was not modulated by list composition in either experiment. The latter finding is consistent with word reading studies that have shown that regularity effects are not altered by the type of the fillers used (Coltheart \& Rastle, 1994; Jared, 1997; Kinoshita \& Lupker, 2002; Waters \& Seidenberg, 1985; Woollams \& Kinoshita, 1997). Finally, the analyses performed on the filler items revealed that high-frequency irregular and regular words were produced faster than nonwords.

The findings do not support the hypothesis that spellers can exert control over the nonlexical processing pathway in written spelling to dictation. In effect, the manipulation that was designed to induce greater reliance on nonlexical processing of the words by including nonwords in the lists did not alter regularity effects on either latencies or spelling errors. However, the findings are compatible with the time-criterion account since we found that the experimental words were produced more slowly when regular and irregular nonwords were used as fillers, as compared with when they were produced with highfrequency irregular and regular words. In effect, according to the time-criterion hypothesis, an effect of list composition should be found when filler type latencies differ and no effect of list composition is expected when different filler types have the same mean latency (Chateau \& Lupker, 2003; Kinoshita \& Lupker, 2003; Lupker et al., 1997; Taylor \& Lupker, 2001).

As far as irregular nonwords are concerned, different plausible orthographic renderings can be used to spell them. Because of possible spelling uncertainty for these nonwords, at least some of them may have been spelled on the basis of some analogy with the spelling of existing words. Indeed, certain studies have shown that the spelling of nonwords can be primed by words (Campbell, 1983; but see also Perry, 2003). Furthermore, a PO regularity effect was observed for high-frequency words, thus suggesting that the nonlexical route played a role.

Our failure to observe a modulation of the regularity effects might be due to the fact that our list composition manipulation was not strong enough to induce greater reliance on nonlexical than on lexical processing. In Experiment 2, a different list composition manipulation was used.

\section{EXPERIMENT 2}

In order to test the hypothesis that the nonlexical route in written spelling to dictation can be strategically controlled, a different list composition manipulation was used. To avoid the problem linked to spelling uncertainty with irregular nonwords, only regular nonwords were used. Because the dual-route view assumes that nonwords can only be spelled via the nonlexical route, the use of regular nonwords should induce reliance on nonlexical processing. According to the dual-route view, the correct spelling of low-frequency irregular words can only be obtained via the lexical route. Moreover, if a list contains only words having atypical PG correspondences, it may be advantageous for the speller to process the words along the faster lexical route because this reduces the risk of producing an incorrect spelling. Consequently, irregular lowfrequency words were used to increase reliance on the lexical route. The same set of regular and irregular target words used in Experiment 1 was used in Experiment 2. According to the attentional strategic control hypothesis, the regularity effect should be larger in the context of regular nonwords, as compared with irregular low-frequency words. In an attempt to increase the power to detect a modulation of the regularity effect as a function of list composition, a within-subjects design was used, unlike in Experiment 1. Likewise, the participants had to produce the same critical set of target words in the two filler envi- 
ronments. According to the time-criterion account, the size of the regularity effect should not be reliably altered by the list composition manipulation. Only a main effect of list composition is predicted when the filler items differ in their speed of initialization, with the result that the experimental words are produced faster with either nonwords or words depending on the fastest items.

\section{Method}

Participants. The participants were 20 psychology students taken from the same pool as in Experiment 1.

Stimuli. The critical stimuli were the same as those used in Experiment 1 . For the word context, irregular low-frequency words were used (the mean word frequency was 4.2 per million, and the mean PO consistency on rime units was .13), while regular nonwords were created for the nonword context.

Apparatus. The same apparatus as in Experiment 1 was used.

Procedure. The procedure was the same as in Experiment 1, except that a within-subjects design was used. Half of the participants started with the nonword context, while the remaining participants started with the word context. As in Experiment 1, for the nonword context condition, the participants were told that they would hear both words and nonwords that they had to write down, using the first spelling that came to mind. For the word context condition, the participants were only told that they would hear words that they would have to write down. The experiment started with practice trials. The entire session lasted about half an hour.

Design. Word type (regular vs. irregular) was a within-subjects factor on participants and a between-subjects factor on items. List composition (regular nonwords vs. low-frequency irregular words) was a within-subjects factor on both participants and items.

\section{Results}

As in Experiment 1, trials were discarded from the latency analyses when a technical problem occurred $(0.13 \%)$, a word was not identified (and a cross was written instead; $0.53 \%$ ), was crossed out $(0 \%)$, or was misspelled $(4.08 \%)$. Also, written latencies longer than two standard deviations above the participant and item means were excluded from the analyses $(0.59 \%$ of the data). Overall, $5.32 \%$ of the data were excluded.

The same kinds of analyses as in Experiment 1 were performed. The order of context (writing words with a nonword context first and then with a word context or the reverse) was introduced as a factor. A reliable main effect of order was observed, but it did not interact with word type and list composition.

Mean written spelling latencies, the standard deviations of these means, and error rates are presented in Table 3.
Latencies. Regular words yielded shorter latencies than did irregular words $\left[F_{1}(1,19)=60.14, M S_{\mathrm{e}}=1,350.231\right.$, $\left.p<.001 ; F_{2}(1,36)=5.35, M S_{\mathrm{e}}=13,275.245, p<.05\right]$. The main effect of list composition was not reliable $\left(F_{\mathrm{s}}<1\right)$. The interaction effect between regularity and list composition was also not reliable $\left[F_{1}(1,19)=2.41\right.$, $M S_{\mathrm{e}}=1,144.04, p=.137 ; F_{2}(1,36)=3.04, M S_{\mathrm{e}}=$ $1,063.373, p=.09]$.

All errors. Irregular words yielded more errors than did regular words $\left[F_{1}(1,19)=11.28, M S_{\mathrm{e}}=.006495\right.$, $\left.p<.01 ; F_{2}(1,36)=5.71, M S_{\mathrm{e}}=.0122, p<.05\right]$. Neither the effect of list composition $\left[F_{1}<1 ; F_{2}(1,36)=1.49\right]$ nor the interaction effect between regularity and list composition were significant (all $F \mathrm{~s}<1$ ).

PP and NPP spelling errors. There were more errors on irregular words than on regular words $\left[F_{1}(1,19)=\right.$ $10.87, M S_{\mathrm{e}}=.006167, p<.01 ; F_{2}(1,36)=7.17, M S_{\mathrm{e}}=$ $.008885, p<.05]$. The main effect of list composition was not significant $\left[F_{1}(1,19)=3.80, M S_{\mathrm{e}}=.000911\right.$, $\left.p=.066 ; F_{2}(1,36)=2.564, M S_{\mathrm{e}}=.001283, p=.118\right]$. Also, the interaction effect between list composition and regularity was not significant $\left(F_{\mathrm{s}}<1\right)$. Exactly the same pattern of results was found on PP spelling errors.

Filler items (words and nonwords). On the latency analysis, low-frequency irregular words and regular nonwords yielded almost identical latencies $(1,081 \mathrm{msec}$ and $1,085 \mathrm{msec}$, respectively; $\left.F_{\mathrm{s}}<1\right)$. There were more errors on words than on nonwords $\left[F_{1}(1,19)=31.82, M S_{\mathrm{e}}=\right.$ $.003359, p<.01 ; F_{2}(1,99)=13.81, M S_{\mathrm{e}}=0.01952$, $p<.001]$.

\section{Discussion}

As in Experiment 1, irregular words yielded longer written latencies and more errors than did regular words. Again, the regularity effect did not vary reliably as a function of list composition, and, numerically, the size of the regularity effect ran in the opposite direction to that predicted by the dual-route view since it was larger with low-frequency irregular words than with regular nonwords. However, the results do support the time-criterion view. As far as the filler items are concerned, regular nonwords and low-frequency irregular words yielded similar written latencies. Given that no effect of list composition was detected, this finding is consistent with the time-criterion hypothesis, which holds that no reliable effect of list composition should be found when filler types have a similar mean latency. When the results cor-

Table 3

Mean Written Spelling Latencies (in Milliseconds), Standard Deviations of the Means, and Error Rates (in Percentages) as a Function of Phonology-to-Orthography Regularity and List Composition in Experiment 2

\begin{tabular}{|c|c|c|c|c|c|c|c|c|}
\hline & \multicolumn{4}{|c|}{ Regular Nonword Context } & \multicolumn{4}{|c|}{ Low-Frequency Irregular Word Context } \\
\hline & \multicolumn{2}{|c|}{ Regular } & \multicolumn{2}{|c|}{ Irregular } & \multicolumn{2}{|c|}{ Regular } & \multicolumn{2}{|c|}{ Irregular } \\
\hline & $M$ & $S D$ & $M$ & $S D$ & $M$ & $S D$ & $M$ & $S D$ \\
\hline Written latency & 917 & 204 & 969 & 204 & 908 & 190 & 984 & 188 \\
\hline All E & \multicolumn{2}{|c|}{2.10} & \multicolumn{2}{|c|}{7.90} & \multicolumn{2}{|c|}{2.60} & \multicolumn{2}{|c|}{8.90} \\
\hline NPP and PP & \multicolumn{2}{|c|}{0.00} & \multicolumn{2}{|c|}{3.95} & \multicolumn{2}{|c|}{0.26} & \multicolumn{2}{|c|}{3.68} \\
\hline
\end{tabular}

Note-All E, all errors included; NPP and PP, nonphonological and phonological spelling errors included. 
responding to the fillers from Experiments 1 and 2 were combined, a post hoc analysis on the items (Tukey HSD tests) revealed that the latencies were shorter for highfrequency irregular and regular filler words $(874 \mathrm{msec})$ than for irregular low-frequency words $(1,080 \mathrm{msec})$ and for regular nonwords $(1,081 \mathrm{msec})$, the latter in turn yielding shorter latencies for irregular and regular nonwords $(1,261 \mathrm{msec})$. As far as the errors are concerned, the same kind of analysis indicates that more errors were produced on irregular low-frequency words than on the other types of filler items. Given that in Experiment 2, regular nonword fillers did not yield longer latencies than did low-frequency irregular words, the inclusion of irregular nonwords seems to be responsible for the list composition effect observed in Experiment 1. However, list composition effects were not strong, since a main effect of list composition was found only in Experiment 1 in the by-items analysis of the latency data. Therefore, a further test of the hypothesis of strategic attentional control over nonlexical and lexical processing in written spelling was conducted in a third experiment, using a stronger context manipulation.

\section{EXPERIMENT 3}

It might be argued that the list composition manipulation used in Experiments 1 and 2 was not strong enough to induce reliable attentional strategic control over the nonlexical route. In Experiment 3, we used the same kind of nonword and word context as in Experiment 2, while intensifying the context manipulation. Indeed, to increase the likelihood of participants relying more or less heavily on the nonlexical route during the first phase of the experiment, half of them had to produce only regular nonwords, while the remaining half produced only low-frequency irregular words. There were 44 items of each type in the two groups. During the second phase of the experiment, depending on the group, the experimental words had to be produced in either the regular nonword or the low-frequency word context used in Experiment 2. The predictions were the same as those put forward for Experiment 2. According to the attentional pathway control hypothesis, spellers should rely more heavily on the nonlexical route when they have produced a large number of nonwords than when they have produced a large number of low-frequency irregular words because the latter can only be produced correctly by means of the lexical route. Therefore, a reliable increase in the size of the regularity effect on written latencies (and on spelling errors) should be observed in the regular nonword context condition, as compared with the low-frequency irregular word condition. In contrast, according to the time-criterion hypothesis, the size of the regularity effect should not vary as a function of the context items. Indeed, the speed of initialization of target words is predicted to differ as a function of the difficulty of producing the context items.

\section{Method}

Participants. The participants were 69 psychology students taken from the same pool as in the previous experiments. They were randomly assigned to the nonword (35) or word (34) condition, respectively.

Stimuli. The critical stimuli were the same as used in Experiments 1 and 2. For the first phase of the experiment, 44 regular nonwords and 44 low-frequency irregular words were used. For the second part of the experiment, the critical stimuli were presented together with the same type of context as that used in the first phase. The nonword and word context items, respectively, were the same as those used in Experiment 2. Overall, the ratio of filler items, compared with the set of critical words, was $72 \%$.

Apparatus. The same apparatus as in Experiments 1 and 2 was used.

Procedure. The procedure was the same as in Experiment 1. During the first phase of the experiment, half of the participants were told that they would hear nonwords that they had to write down, using the first spelling that came to mind, and the remaining half were told that they would hear words that they had to write down. During the second phase of the experiment, the participants in the nonword context condition were told that they would continue to hear nonwords that they had to write down, as well as words that they had to write down, using the correct spelling for each. For the word context condition, the participants were told that they would again hear words that they had to write down. The experiment started with practice trials. The entire session lasted about half an hour.

Design. Word type (regular vs. irregular) was a within-subjects factor on participants and a between-subjects factor on items. List composition (regular nonwords vs. low-frequency irregular words) was a between-subjects factor on participants and a within-subjects factor on items.

\section{Results}

As in the previous experiments, trials were discarded from the latency analyses when a technical problem occurred $(0.11 \%)$, a word was not identified (and a cross was written instead; $0.11 \%$ ), was crossed out $(0.08 \%)$, or was misspelled (6.82\%). Furthermore, written latencies longer

Table 4

Mean Written Spelling Latencies (in Milliseconds), Standard Deviations of the Means, and Error Rates (in Percentages) as a Function of Phonology-to-Orthography Regularity and List Composition in Experiment 3

\begin{tabular}{|c|c|c|c|c|c|c|c|c|}
\hline & \multicolumn{4}{|c|}{ Regular Nonword Context } & \multicolumn{4}{|c|}{ Low-Frequency Irregular Word Context } \\
\hline & \multicolumn{2}{|c|}{ Regular } & \multicolumn{2}{|c|}{ Irregular } & \multicolumn{2}{|c|}{ Regular } & \multicolumn{2}{|c|}{ Irregular } \\
\hline & $M$ & $S D$ & $M$ & $S D$ & $M$ & $S D$ & $M$ & $S D$ \\
\hline Written latency & 902 & 181 & 918 & 186 & 1,021 & 169 & 1,041 & 174 \\
\hline All E & \multicolumn{2}{|c|}{4.80} & \multicolumn{2}{|c|}{13.70} & \multicolumn{2}{|c|}{4.20} & \multicolumn{2}{|c|}{10.50} \\
\hline NPP and PP & \multicolumn{2}{|c|}{3.90} & \multicolumn{2}{|c|}{12.30} & \multicolumn{2}{|c|}{2.60} & \multicolumn{2}{|c|}{9.00} \\
\hline
\end{tabular}

Note-All E, all errors included; NPP and PP, nonphonological and phonological spelling errors included. 
than two standard deviations above the participant and item means were excluded from the analyses $(0.99 \%$ of the data). Overall, $8.11 \%$ of the data were excluded.

The same kinds of analyses as in Experiments 1 and 2 were performed. Mean written spelling latencies, the standard deviations of these means, and error rates are presented in Table 4.

Latencies. Regular words yielded shorter latencies than did irregular words $\left[F_{1}(1,67)=12.91, M S_{\mathrm{e}}=\right.$ $856.36, p<.001]$, although the effect was not reliable on the items $\left(F_{2}<1\right)$. The main effect of list composition was reliable $\left[F_{1}(1,67)=8.08, M S_{\mathrm{e}}=31,230.70, p<.01\right.$; $\left.F_{2}(1,36)=239.02, M S_{\mathrm{e}}=1,212.45, p<.001\right]$, indicating that the experimental words were produced faster in a regular nonword context than in a low-frequency irregular word context. The interaction effect between regularity and list composition was not reliable $\left(F_{\mathbf{s}}<1\right)$.

All errors. Irregular words yielded more errors than did regular words $\left[F_{1}(1,67)=55.18, M S_{\mathrm{e}}=.000362\right.$, $\left.p<.001 ; F_{2}(1,36)=5.63, M S_{\mathrm{e}}=.009773, p<.05\right]$. Neither the effect of list composition $\left[F_{1}(1,67)=2.15\right.$, $\left.p=.14 ; F_{2}(1,36)=2.77, p=.10\right]$ nor the interaction effect between regularity and list composition were significant $\left[F_{1}(1,67)=1.52 ; F_{2}(1,36)=1.23\right]$.

PP spelling errors. There were more errors on irregular words than on regular words $\left[F_{1}(1,67)=69.98, M S_{\mathrm{e}}=\right.$ $.001831, p<.001 ; F_{2}(1,36)=9.23, M S_{\mathrm{e}}=.003824$, $p<.01]$. The main effect of list composition was not significant $\left(F_{\mathrm{S}}<1\right)$. Also, the interaction effect between list composition and regularity was not significant $(F \mathrm{~s}<1)$. Exactly the same pattern of results was found on PP and NPP spelling errors.

Filler items (words and nonwords) used for the second phase of the experiment. On the latency analysis, low-frequency irregular words were produced more slowly $(1,086 \mathrm{msec})$ than regular nonwords $(935 \mathrm{msec})$ $\left[F_{1}(1,67)=10.97, M S_{\mathrm{e}}=35,730.83, p<.01 ; F_{2}(1,86)=\right.$ $\left.80.82, M S_{\mathrm{e}}=6,616.14, p<.001\right]$. There were more errors on words $(13.49 \%)$ than on nonwords $(7.6 \%)\left[F_{1}(1,67)=\right.$ $12.95, M S_{\mathrm{e}}=.006237, p<.01 ; F_{2}(1,86)=6.76, M S_{\mathrm{e}}=$ $.01517, p<.05]$.

Filler items (words and nonwords) used for the first phase of the experiment. The regularity effect was reliable on both participants and items $\left[F_{1}(1,67)=21.38\right.$, $M S_{\mathrm{e}}=32,871.13, p<.001 ; F_{2}(1,75)=85.05, M S_{\mathrm{e}}=$ $9,173.5, p<.001]$, with latencies on regular nonwords being faster $(926 \mathrm{msec})$ than on low-frequency irregular words $(1,128 \mathrm{msec})$. The number of errors did not reliably differ between the two types of items $(F \mathrm{~s}<1)$.

\section{Discussion}

Using the same critical set of regular and irregular words as those used in Experiments 1 and 2, but with a stronger list composition manipulation, we again found no reliable modulation of the size of the regularity effect on either written latencies or spelling errors. Therefore, the evidence available from our experiments does not support the attentional control pathway hypothesis. In- deed, our results are better accounted for by the timecriterion hypothesis. In effect, we found that the critical words were produced faster in a regular nonword context $(910.5 \mathrm{msec})$ than in a low-frequency irregular word context (1,032 msec), whereas in Experiment 2, we found that the same set of words was produced at virtually the same speed in a regular nonword context $(943 \mathrm{msec})$ and in a low-frequency irregular word context $(946 \mathrm{msec})$. In accordance with the time-criterion hypothesis, we found that a main effect of list composition is reliably observed on the production latency of the critical set of words when the filler items differ in their overall speed of initialization (Experiment 3) but not when the filler items are equivalent in terms of speed of initialization (Experiment 2). Additional item analyses were performed on the fillers to compare across Experiments 1 and 2. We found that the regular nonwords in Experiment 3 were produced faster than the low-frequency irregular words in Experiments 2 and 3 and the regular nonwords in Experiment 2 (the latter three types of fillers did not reliably differ). Given that the context items were the same in the two experiments, the initialization latencies differ because in the present experiment, unlike in Experiment 2 , there was a phase before the experiment proper during which the participants had to produce either a large set of regular nonwords or low-frequency irregular words. Because the irregular nonwords that were produced before the experiment proper-namely, the first phase of the experiment - took longer to produce than did the regular nonwords, the difference in naming speed is attributable to a change in the setting of the criterion that initializes writing.

Our findings are nicely accounted for by the timecriterion hypothesis but provide strong evidence against the hypothesis of strategic attentional control over the nonlexical route. In effect, according to the attentional control hypothesis, it is the nature of the filler items (words vs. nonwords) that matters and not the degree of difficulty involved in the production of the fillers. Nevertheless, a further test of this hypothesis was conducted in a fourth experiment, using a different methodology.

\section{EXPERIMENT 4}

In Experiment 4, a different methodology was used to test the strategic control hypothesis in written spelling to dictation. The participants were required to produce the same critical set of words as used in Experiments 1 to 3, either under time pressure or in response to standard naming instructions emphasizing both speed and accuracy. To this end, in the time pressure condition, the participants heard an auditory signal (a beep) and had to try to initialize their writing response before the beep. Again, regularity effects were used as an index of nonlexical processing. In contrast to the three experiments reported above, no fillers were included.

If the participants are able to deemphasize nonlexical processing, they should do so when the instructions force 
them to speed up their response initialization. In effect, because lexical processing is assumed to be more automatized than is nonlexical processing, the spelling responses should be based on the output provided by the "fastest" route in speeded written spelling - namely, the lexical route. Therefore, the size of the regularity effect on both written latencies and spelling errors should be smaller when spelling under a deadline condition than when spelling under a standard spelling condition (in which speed is emphasized but to a lesser extent). The naming-to-deadline procedure has already been used in spoken picture naming to investigate the levels of representations involved in this task and their time course of activation (e.g., Vitkovitch, Humphreys, \& Lloyd-Jones, 1993). It has been found that naming to deadline has the effect of increasing the naming error rate dramatically. Another method that has been used to increase the speed of responding in word naming has been to decrease the interstimulus interval (e.g., Jared, 1997). According to the time-criterion hypothesis, the manipulation designed to speed up the initialization of the written response should have the effect of placing the criterion earlier than is the case with standard written spelling instructions. It should have no effect on the nature of the processing. Therefore, a main effect of instructions is predicted but no reliable alteration of the size of the regularity effect is predicted.

\section{Method}

Participants. The participants were 32 psychology students taken from the same pool as in the previous experiments.

Stimuli. The critical stimuli were the same as those used in Experiments 1,2 , and 3 .

Apparatus. The same apparatus as in the previous experiments was also used here.

Procedure. The participants were randomly assigned either to the standard written spelling production condition (16) or to the deadline written spelling production condition (16). The instructions in the standard written spelling production condition were the same as in Experiments 1, 2, and 3-namely, both speed and accuracy were emphasized. In the deadline written spelling production condition, the participants were told that they would hear a beep after the auditory presentation of the item to be spelled and that they would have to do their best to initiate their written responses before the beep, but should not do so at the expense of response accuracy. More precisely, each experimental trial took the form of the following sequence of events: A ready signal (“*”) was presented for $1,000 \mathrm{msec}$, followed $200 \mathrm{msec}$ later by the auditory presentation of the word. The beep was presented 1,100 msec after word onset.

Design. Instructions (standard written spelling vs. deadline written spelling) was a between-subjects factor on participants and a within-subjects factor participants on items. Word type (regular vs. irregular) was within-subjects factor on participants and a betweensubjects factor on items.

\section{Results and Discussion}

As in Experiments 1, 2, and 3, trials were discarded from the latency analyses when a technical problem occurred $(1.07 \%)$, a word was not identified (and a cross was written instead; $1.39 \%)$, was crossed out $(0.08 \%)$, or was misspelled (4.44\%). Written latencies longer than two standard deviations above the participant and item means were also excluded from the analyses $(1.31 \%$ of the data). Overall, $8.29 \%$ of the data were excluded.

Mean written spelling latencies, the standard deviations of these means, and error rates are presented in Table 5.

Latencies. Written latencies were shorter on regular than on irregular words $\left[F_{1}(1,30)=29.77, M S_{\mathrm{e}}=1,775\right.$, $\left.p<.001 ; F_{2}(1,36)=10.32, M S_{\mathrm{e}}=8,001.5, p<.01\right]$. Written latencies were shorter in response to the deadline instruction than to the standard writing instruction $\left[F_{1}(1,30)=11.49, M S_{\mathrm{e}}=55,557.92, p<.01 ; F_{2}(1,36)=\right.$ $\left.769.95, M S_{\mathrm{e}}=1,356.77, p<.001\right]$. The regularity effect was not found to reliably differ as a function of instruction $\left[F_{1}(1,30)=1.72 ; F_{2}(1,36)=1.73\right]$.

All errors. There were more errors on irregular than on regular words $\left[F_{1}(1,30)=13.91, M S_{\mathrm{e}}=.004034\right.$, $\left.p<.01 ; F_{2}(1,36)=3.96, M S_{\mathrm{e}}=.016688, p=.054\right]$. Also, more errors were observed with the deadline instruction than with the standard instruction $\left[F_{1}(1,30)=\right.$ $5.85, M S_{\mathrm{e}}=.005003, p<.05 ; F_{2}(1,36)=7.649, M S_{\mathrm{e}}=$ $.00474, p<.01]$. The regularity effect was not found to reliably differ as a function of instruction $\left[F_{1}(1,30)=\right.$ $\left.3.48 ; F_{2}(1,36)=3.73, M S_{\mathrm{e}}=.00474\right]$.

PP and NPP spelling errors. The effect of regularity was significant on both participants and items $\left[F_{1}(1,30)=\right.$ $24.22, M S_{\mathrm{e}}=.002066, p<.001 ; F_{2}(1,36)=4.27, M S_{\mathrm{e}}=$ $.013187, p<.05]$. Neither the main effect of instruction $\left[F_{1}(1,30)=1.25 ; F_{2}(1,36)=1.45\right]$ nor the interaction effect between regularity and instruction were reliable $\left[F_{1}(1,30)=2.10 ; F_{2}(1,36)=2.18\right]$. Exactly the same results were found in the analysis that only took account of PP spelling errors.

To summarize, the findings from Experiment 4 are also extremely difficult to reconcile with the attentional control pathway hypothesis. If spellers are indeed able to control nonlexical processing, and assuming that the non-

Table 5

Mean Written Spelling Latencies (in Milliseconds), Standard Deviations of the Means, and Error Rates (in Percentages) in Experiment 4

\begin{tabular}{|c|c|c|c|c|c|c|c|c|}
\hline & \multicolumn{4}{|c|}{ Standard } & \multicolumn{4}{|c|}{ Deadline } \\
\hline & \multicolumn{2}{|c|}{ Regular } & \multicolumn{2}{|c|}{ Irregular } & \multicolumn{2}{|c|}{ Regular } & \multicolumn{2}{|c|}{ Irregular } \\
\hline & $M$ & $S D$ & $M$ & $S D$ & $M$ & $S D$ & $M$ & $S D$ \\
\hline Written latency & 988 & 187 & 1,060 & 212 & 803 & 108 & 845 & 151 \\
\hline All E & \multicolumn{2}{|c|}{4.60} & \multicolumn{2}{|c|}{7.57} & \multicolumn{2}{|c|}{5.92} & \multicolumn{2}{|c|}{14.80} \\
\hline NPP and PP & \multicolumn{2}{|c|}{2.02} & \multicolumn{2}{|c|}{5.67} & \multicolumn{2}{|c|}{1.64} & \multicolumn{2}{|c|}{8.88} \\
\hline
\end{tabular}

Note-All E, all errors included; NPP and PP, nonphonological and phonological spelling errors included. 
lexical route is less automatized and slower than the lexical route, they should rely to a greater extent on the output provided by the fastest route - that is, the output from the lexical route-when subjected to time pressure. Therefore, regularity effects, which are assumed to index the involvement of the nonlexical route, should have been altered by the instructions emphasizing speed, as compared with standard written spelling instructions. However, the deadline manipulation was successful since the latencies were $200 \mathrm{msec}$ faster than in the standard written spelling condition. Importantly, writing in response to deadline instructions did not result in an increase in spelling error rates. This indicates that spellers were able to adjust the time taken to initiate a spelling response but not at the expense of spelling response accuracy. The findings of Experiments 1 to 4 concerning spelling errors suggest that they do not result from online competition between alternative orthographic codes generated by the nonlexical processing pathway (performance errors) and are, indeed, better characterized as being due to the storage of incorrect spellings for some words. We will return to this issue in the General Discussion section.

\section{GENERAL DISCUSSION}

The dominant view of written spelling to dictation is the symbolic dual-route view, which assumes that the written spelling to dictation of words involves two processing pathways: the lexical and nonlexical routes (Rapp et al., 2002). The core assumption of the dual-route view is that the knowledge of sound-spelling relationships is stored individually from the knowledge of individual word spellings. The lexical route involves the retrieval of individual orthographic patterns in the mental lexicon corresponding to words, whereas the nonlexical route makes use of subword knowledge consisting of phoneme-grapheme mappings (Rapp et al., 2002). The two routes also differ in their processing characteristics. The nonlexical route is less automatized and slower than the lexical route.

As set out in the introduction of this article, various lines of evidence support the dual-route view of spelling to dictation. However, compared with reading aloud, the dual-route view in spelling has not as yet given rise to the same amount of theoretical and empirical research. As a result, the dual-route view of spelling to dictation is less elaborated than that of reading aloud. For instance, whereas the issue of whether the two routes can be strategically controlled has given rise to a number of studies and is still being debated (e.g., Chateau \& Lupker, 2003; Kinoshita \& Lupker, 2002), to our knowledge, no study has as yet been conducted on this topic in the field of written spelling. The motivation for examining whether the two routes can be subjected to strategic control in written spelling was that written spelling is a less frequently practiced skill than reading aloud and that it therefore provides an enhanced opportunity to observe attentional strategic control.
In four experiments, we found no support for the claim that the nonlexical route might be under strategic control. In three experiments, participants had to produce regular and irregular words mixed with nonwords or with words. In Experiment 1, a between-subjects design was used, and the critical set of regular and irregular words was presented either with regular and irregular nonwords or with high-frequency regular and irregular words. In Experiment 2, a within-subjects design was employed, in which participants wrote down the same set of regular and irregular words in the context of regular nonwords and in that of low-frequency irregular words. Experiment 3 was a replication of Experiment 2 with a stronger list composition manipulation and a between-subjects design. The rationale for using list composition manipulations was to induce greater reliance on the nonlexical, as opposed to the lexical, processing pathway. Because dualroute theorists assume that regularity effects - namely, longer latencies and more errors on irregular words than on regular words - signal the involvement of the nonlexical route, any reliable sizeable modulation of regularity effects is taken as evidence for the strategic control hypothesis. In Experiments 1 to 3, the list composition manipulations did not reliably modulate the size of regularity effects. In Experiment 4, a different methodology was used to test the strategic control hypothesis. The participants had to produce regular and irregular words, either in response to standard written spelling or deadline instructions. Because the lexical route is assumed to be faster than the nonlexical route, the assumption was that the spelling responses would be based on the fastest route, namely, the lexical route, under speeded instruction. As a result, regularity effects should be reduced when spelling under deadline instructions, as compared with spelling under standard instructions. In this experiment, the size of the regularity effects on both latencies and errors were again not reliably modulated.

Taken overall, the observation that neither list composition manipulations nor the instructions to increase speed modulated the size of regularity effects on either latencies or errors is extremely difficult to account for if the particular assumption that the nonlexical processing can be strategically controlled is adopted within a dual-route view. The findings are consistent with word reading studies that have shown that regularity effects are not reliably altered by list composition (Chateau \& Lupker, 2003; Coltheart \& Rastle, 1994; Jared, 1997; Kinoshita \& Lupker, 2002, 2003). Indeed, thus far, evidence for strategic control over the nonlexical route in word reading is weak at best. One example here is the Zevin and Balota (2000) study, which is the only one to show a modulation of the regularity effect in reading aloud that is consistent with the strategic control hypothesis - that is to say, a larger regularity effect on latencies and a higher percentage of regularization errors in the nonword prime condition, compared with the exception word prime condition. However, using a similar methodology, Kinoshita and Lupker (2003) failed to produce a reliable modulation of the size of the regularity effect. 
The findings from Experiment 4 clearly revealed that spellers are able to speed up their responses to a substantial degree, but not at the expense of response accuracy, since the number of spelling errors remained the same as when standard spelling instructions were given. This finding differs from that obtained by Strain et al. (1995) in word reading. Under standard word naming conditions, they found main effects of regularity and imageability and an interaction between the two, with the result that exception words were named more slowly than regular words but only when the words were of low imageability. Under speeded naming conditions, they did not find a main effect of regularity but a similar, although weaker, interaction between regularity and imageability. According to Strain et al. (1995), speeded naming has the effect of reducing the semantic contribution to phonological encoding in word reading. Gerhand and Barry (1999) have suggested that the absence of a main effect of regularity in Strain et al.'s (1995) study was due to a reduction of the contribution of assembled phonology.

As far as written spelling to dictation is concerned, the absence of a reliable modification of the size of regularity effects in either latencies or errors strongly suggests that the contribution of the nonlexical pathway is fast and mandatory. Thus, our results cast doubt on versions of the dual-route view that assume that the nonlexical route is slower and more attentionally demanding than the lexical route (Kreiner, 1996). Indeed, as we have argued, because written spelling to dictation is a less practiced activity than reading aloud, the former is less automatized than the latter, thus leading us to expect that the spelling-to-dictation task should be more likely to reveal evidence in favor of the strategic control hypothesis.

Could it be the case that our failure to detect a reliable modulation of the size of regularity effects on latencies was due to a lack of statistical power? The size of the regularity effect on latency was $11 \mathrm{msec}$ larger in a nonword context than in a word context in Experiment 1,24 msec smaller in Experiment 2, and 4 msec smaller in Experiment 3. In Experiment 4, the size of the regularity effect was $30 \mathrm{msec}$ smaller in the deadline condition than in the standard condition. We performed power analyses in order to determine whether our experiments had sufficient power to detect a reliable alteration of the size of the regularity effect on the onset latencies as predicted by the attentional control pathway hypothesis.

Considering the by-participants analyses on written latencies, the observed interaction effect sizes ( $f$, see Cohen, 1988) were equal to .082, .05, and .24 in Experiments 1, 3, and 4, respectively (we did not consider Experiment 2 , because the observed interaction pattern worked in the opposite direction to the one predicted by the control pathway hypothesis). To use Cohen's (1992) terminology, the effect sizes were small in Experiments 1 and 3 and medium in Experiment 4. If we consider these effect sizes to be true effect sizes, the observed powers are about $.07, .08$, and .25 , which is clearly weak. However, this aspect can be accounted for more satisfactorily by effect sizes than by insufficient sample sizes. In effect, to obtain a power of .80 (which is the reference power given by Cohen, 1992) would have required sample sizes of more than 200 participants in Experiments 1 and 3, and 71 in Experiment 4, which is far greater than the numbers used in most psycholinguistic experiments. The results were roughly the same, as far as the error analyses are concerned.

As in word reading, the data obtained for spelling can be accounted for more easily in terms of a time-criterion hypothesis. According to this hypothesis, spellers do not always initiate writing as soon as they are ready to do so. The position of the time criterion is set on the basis of the relative difficulty of the items in the list and the type of writing instruction. The time-criterion hypothesis predicts an effect of list composition when the filler types differ in their overall mean latency. In line with this hypothesis, the findings of Experiment 1 suggest that the inclusion of regular and irregular nonwords delays the initiation of writing, and those of Experiment 2 show no reliable effect of list composition, with the fillers having similar mean latencies. The findings of Experiment 3 are particularly interesting. With a stronger list composition manipulation than the one used in Experiments 1 and 2 (by including a phase during which certain participants are asked to produce a large set of regular nonwords while others are asked to produce a large number of lowfrequency irregular words), the nonword and word context items that were produced at virtually the same speed in Experiment 2 were produced at different speeds in Experiment 3 , with nonwords being produced more rapidly than low-frequency irregular words.

Also consistent with the time-criterion account is the fact that the findings from Experiment 4 show that emphasizing speed has the effect of decreasing the latencies of the spelling responses. An issue not addressed in the present article is whether the writing durations are also affected by speeded writing instructions. The issue is a very important one (and will certainly be the focus of future studies of our own) because it may inform us of whether "central" processes can "cascade" into graphic execution. Using Stroop tasks, Kello, Plaut, and MacWhinney (2000) have shown that a deadline naming procedure had the effect of accelerating latencies and also of shortening the overall response durations. According to Kello et al., the speech production system is flexible, task dependent, and demand dependent. However, also using a deadline naming procedure, Damian (2003) failed to find evidence for an influence of central mechanisms on response execution in speech production.

Across the four experiments, the spelling error rates were unaffected by either list composition or by speed instructions. Thus far, we have assumed that the list composition manipulation emphasizing nonlexical processing should have resulted in an increase in spelling errors, reasoning that the nonlexical route is responsible for spelling errors and especially phonologically plausible errors (e.g., Folk, Rapp, \& Goldrick, 2002). In effect, the nonlexical route provides the most common render- 
ings for irregular words. When irregular words include renderings that are not the most common ones, some degree of conflict arises between the orthographic codes generated by the lexical route and those generated by the nonlexical route. The renderings generated by the nonlexical route can, under some conditions, be erroneously selected and thus result in a PPE. There is evidence in patients that the nonlexical route underlies the generation of PPEs (e.g., Folk et al., 2002; Rapp et al., 2002). Folk et al. have described a patient, M.M.D., who exhibited a number of PPEs in spelling to dictation. M.M.D. exhibited a strong deficit of the lexical route but only a moderate deficit of the nonlexical route. When the patient was required to produce the spelling of words under articulatory suppression conditions (i.e., repeating a meaningless sequence while spelling), the number of PPEs decreased dramatically, compared with spelling words without articulatory suppression. This pattern of performance has been interpreted as providing evidence that the nonlexical route is responsible for the generation of PPEs. According to this account, PPEs are the result of competition between the output provided by the lexical and nonlexical routes, respectively. When the conditions lead to a reduction of the involvement of the nonlexical route, there are fewer opportunities for competition between the output provided by the two routes and, as a result, fewer PPEs are generated. In light of this pattern of disturbance in a patient, placing greater reliance on lexical processing should result in a decrease in PPEs in normals. However, in Experiment 4, PPEs were unaffected by speed instructions. The findings of Experiment 4 are consistent with Colombo and Tabossi (1992), who also found that the use of a deadline procedure did not result in an increase in error rates while the naming latencies decreased.

Spelling errors can, however, also be due to the lexical route, one example of this being lexical substitution errors. It must be acknowledged that the interpretation of PPEs in our experiments is somewhat ambiguous because at least some of them could be due to the fact that some participants had no idea of the spelling of certain words. Therefore, the nonlexical route might play a role in computing a plausible spelling without any conflict arising from the lexical route. Also, PPEs could result from the storage of an incorrect spelling for some words that participants are not aware of. Indeed, certain findings in the literature suggest that spelling errors are not primarily due to on-line competition between nonlexical and lexical processing - namely, performance errorsbut are better accounted for by assuming that erroneous spellings for some words are stored in the orthographic lexicon. In a previous study, we found that the number of spelling errors remained the same in an untimed written naming task in which participants were encouraged to check their spellings (Bonin et al., 2001). As far as the spelling errors from Experiment 2 are concerned, a further error analysis does indeed strongly suggest that a large proportion of them result from inaccurate spelling knowledge. In effect, out of 52 spelling errors, we found 32 cases corresponding to the same spelling error produced by the participants across the two experimental conditions, 8 cases corresponding to 2 different spelling errors, and 12 cases corresponding to either a first correct spelling and then to a spelling error or the reverse. The hypothesis that spelling errors are better characterized as being "knowledge" errors is compatible with the observation that college students are sometimes more confident about their own misspellings than about the correct spelling of low-frequency words (Holmes \& Carruthers, 1998). One issue that deserves future research is how incorrect word spellings can become established in memory. In Bonin et al. (2001), we put forward the idea that the influence of the consistency of the mappings between sound and orthographic units corresponding to words may be viewed as a self-teaching mechanism, as Jorm and Share (1983) have suggested in connection with word reading. The spelling that is produced for a word may be stabilized in memory when it matches its corresponding phonological form. Thus, incorrect spellings would be reinforced when they are produced in a phonologically plausible manner.

Before concluding, it should be remembered that the topic of skilled written spelling to dictation has given rise to a smaller volume of research than has skilled reading. The dual-route view is the dominant view of spelling to dictation, but in spelling to dictation there is no equivalent of the computational version of the dual-route cascaded model of reading aloud (Coltheart et al., 2001). Moreover, although certain connectionist single-route alternatives in spelling to dictation have been put forward in spelling, these are far less advanced than those put forward in reading aloud. Maybe because of this, the issue of whether sound-spelling knowledge is better characterized as a set of phoneme-grapheme rules or degrees of consistency has not yet given rise to any focused research. Although beyond the scope of the present study, it remains to be established by future work whether sound-spelling regularity or sound-spelling consistency best characterizes the difficulty associated with spelling. In reading aloud, this issue has been systematically investigated (e.g., Cortese \& Simpson, 2000; Jared, 2002). Jared (2002) has found evidence that the regularity effect is more robust when exception words have a low summed frequency of friends and a high frequency of enemies than when exception words have a high summed frequency of friends and a low frequency of enemies. This finding seems to indicate that consistency in word reading matters more than does regularity. In spelling, future empirical and modeling work is clearly needed in order to establish whether the same evidence is obtained.

To conclude, our study makes a valuable contribution by showing that regularity effects in written spelling to dictation are immune to manipulations that are intended to increase or decrease reliance on nonlexical processing. It also suggests that sublexical codes are obligatorily involved in written spelling to dictation and that adults do 
not have attentional strategic control over nonlexical and lexical processing in written spelling to dictation. Thus, at a theoretical level the implication is that models of written spelling to dictation do not need to include a control mechanism responsible for change in reliance on nonlexical processing. However, spellers are able to generate an internal deadline criterion for when to initialize their writing responses, and this varies as a function of the task demands and stimulus characteristics.

\section{REFERENCES}

Alario, F. X., \& Ferrand, L. (1999). A set of 400 pictures standardized for French: Norms for name agreement, image agreement, familiarity, visual complexity, image variability, and age of acquisition. Behavior Research Methods, Instruments, \& Computers, 31, 531-552.

BALUCH, B., \& BESNER, D. (1991). Visual word recognition: Evidence for strategic control of lexical and nonlexical routines in oral reading. Journal of Experimental Psychology: Learning, Memory, \& Cognition, 17, 644-652.

BARRY, C. (1994). Spelling routes (or roots or rutes). In G. D. A. Brown $\&$ N. C. Ellis (Eds.), Handbook of spelling: Theory, process and intervention (pp. 27-49). Chichester, U.K.: Wiley.

BARrY, C., \& SEYMOUR, P. H. K. (1988). Lexical priming and sound-tospelling contingency effects in nonword spelling. Quarterly Journal of Experimental Psychology, 40A, 5-40.

BAXTER, D. M., \& WARrINGTON, E. K. (1985). Category specific phonological dysgraphia. Neuropsychologia, 23, 653-666.

BAXTER, D. M., \& WARRINGTON, E. K. (1987). Transcoding sound to spelling: Single or multiple sound unit correspondences? Cortex, 23, 11-28.

BeAuvoIs, M.-F., \& Dérouesné, J. (1981). Lexical or orthographic agraphia. Brain, 104, 21-49.

Behrmann, M., \& BuB, D. (1992). Surface dyslexia and dysgraphia: Dual routes, single lexicon. Cognitive Neuropsychology, 9, 209-251.

Bonin, P., \& MÉOT, A. (2002). Writing to dictation in real time in adults: What are the determinants of written latencies? In S. P. Shohov (Ed.), Advances in psychology research: Vol. 16 (pp. 139-165). New York: NovaScience.

Bonin, P., Méot, A., Aubert, L., Malardier, N., Niedenthal, P., \& CAPElle-ToczeK, M.-C. (2003). Normes de concrétude, de valeur d'imagerie, de fréquence subjective et de valence émotionnelle pour 867 mots [Concreteness, imageability, subjective frequency and emotional valence norms for 867 words]. L'Année Psychologique, 104, 655-694.

Bonin, P., Peereman, R., \& Fayol, M. (2001). Do phonological codes constrain the selection of orthographic codes in written picture naming? Journal of Memory \& Language, 45, 688-720.

Bonin, P., Peereman, R., Malardier, N., Méot, A., \& Chalard, M. (2003). A set of 299 pictures for psycholinguistic studies: French norms for name agreement, image agreement, conceptual familiarity, visual complexity, image variability, age of acquisition, and naming latencies. Behavior Research Methods, Instruments, \& Computers, 35, 158-167.

Brown, G. D. A., \& Loosemore, R. P. W. (1994). Computational approaches to normal and impaired spelling. In G. D. A. Brown \& N. C. Ellis (Eds.), Handbook of spelling: Theory, process and intervention (pp. 319-335). Chichester, U.K.: Wiley.

Bub, D., \& Kertesz, A. (1982). Deep agraphia. Brain \& Language, 16, 146-165.

Campbell, R. (1983). Writing nonword to dictation. Brain \& Language, 19, 153-178.

Chateau, D., \& Lupker, S. J. (2003). Strategic effects in word naming: Examining the route emphasis versus time-criterion accounts. Journal of Experimental Psychology: Human Perception \& Performance, 29, 139-151.

COHEN, J. (1988). Statistical power analysis for the behavioral sciences. Hillsdale, NJ: Erlbaum.

Cohen, J. (1992). A power primer. Psychological Bulletin, 112, 155159.
Cohen, J., MacWhinney, B., Flatt, M., \& Provost, J. (1993). PsyScope: An interactive graphic system for designing and controlling experiments in the psychology laboratory using Macintosh computers. Behavior Research Methods, Instruments, \& Computers, 25, 257-271.

Colombo, L., \& TABossi, P. (1992). Strategies and stress assignment: Evidence from a shallow orthography. In R. Frost \& L. Katz (Eds.), Orthography, phonology, morphology, and meaning (pp. 319-399). Amsterdam: North-Holland.

Coltheart, M., \& Rastle, K. (1994). Serial processing in reading aloud: Evidence for dual-route models of reading. Journal of Experimental Psychology: Human Perception \& Performance, 20, 11971211.

Coltheart, M., Rastle, K., Perry, C., Langdon, R., \& Ziegler, J. (2001). DRC: A dual route cascaded model of visual word recognition and reading aloud. Psychological Review, 108, 204-256.

Content, A., Mousty, P., \& Radeau, M. (1990). Brulex: Une base de données informatisée pour le français écrit et parlé. L'Année Psychologique, 90, 551-566.

Content, A., \& RAdeAU, M. (1988). Données statistiques sur la structure orthographique du français. Cahiers de Psychologie Cognitive, 8, 399-404.

Cortese, M. J., \& Simpson, G. B. (2000). Regularity effects in word naming: What are they? Memory \& Cognition, 28, 1269-1276.

Cortese, M. J., Simpson, G. B., \& Woolsey, S. (1997). Effects of association and imageability on phonological mapping. Psychonomic Bulletin \& Review, 4, 226-231.

DAMIAN, M. F. (2003). Articulatory duration in single word speech production. Journal of Experimental Psychology: Learning, Memory, \& Cognition, 29, 416-431.

FoLK, J. R., RAPP, B., \& GoLDRICK, M. (2002). The interaction of lexical and sublexical information in spelling: What's the point? Cognitive Neuropsychology, 19, 653-671.

GERHAND, S., \& BARRY, C. (1999). Age-of-acquisition and frequency effects in speeded word naming. Cognition, 73, B27-B36.

Goodman, R. A., \& Caramazza, A. (1986). Aspects of the spelling process: Evidence from a case of acquired dysgraphia. Language \& Cognitive Processes, 1, 263-296.

HOLMES, V. M., \& CARRUTHERS, J. (1998). The relation between reading and spelling in skilled adult readers. Journal of Memory \& Language, 39, 264-289.

Houghton, G., \& ZoRZI, M. (2003). Normal and impaired spelling in a connectionist dual route architecture. Cognitive Neuropsychology, 20, 115-162.

JARED, D. (1997). Evidence that strategy effects in word naming reflect changes in output timing rather than changes in processing route. Journal of Experimental Psychology: Learning, Memory, \& Cognition, 23, 1424-1438.

JARED, D. (2002). Spelling-sound consistency and regularity effects in word naming. Journal of Memory \& Language, 46, 723-750.

JoRM, A. F., \& SHARE, D. L. (1983). Phonological recoding and reading acquisition. Applied Psycholinguistics, 4, 103-147.

Kello, C. T., Plaut, D. C., \& MacWhinney, B. (2000). The task dependence of staged versus cascaded processing: An empirical and computational study of Stroop interference in speech production. Journal of Experimental Psychology: General, 129, 340-360.

KINOSHITA, S., \& LUPKER, S. J. (2002). Effects of filler type in naming: Change in time criterion or attentional control of pathways? Memory \& Cognition, 30, 1277-1287.

KINOSHITA, S., \& LUPKER, S. J. (2003). Priming and attentional control of lexical and sublexical pathways in naming: A reevaluation. Journal of Experimental Psychology: Learning, Memory, \& Cognition, 29, 405-415.

KREINER, D. S. (1996). Effects of word familiarity and phoneme-tographeme polygraphy on oral spelling time and accuracy. Psychological Record, 46, 49-70.

LUPKER, S. J., BROWN, P., \& COLOMBO, L. (1997). Strategic control in a naming task: Changing routes or changing deadlines? Journal of Experimental Psychology: Learning, Memory, \& Cognition, 23, 570590.

Marcus, S. M., \& Frauenfelder, U. H. (1985). Word recognitionuniqueness or deviation? A theoretical note. Language \& Cognitive Processes, 1, 163-169. 
Monsell, S., Patterson, K. E., Graham, A., Hughes, C. H., \& MilROY, R. (1992). Lexical and sublexical translation of spelling to sound: Strategic anticipation of lexical status. Journal of Experimental Psychology: Learning, Memory, \& Cognition, 18, 452-467.

New, B., Pallier, C., Ferrand, L., \& Matos, R. (2001). Une base de données lexicales du français contemporain sur internet: LEXIQUE [A lexical database of contemporary French on the Internet: LEXIQUE]. L'Année Psychologique, 101, 447-462 (Available at http://www.lexique. org).

OLSON, A., \& Caramazza, A. (1994). Representations and connectionist models: The NETspell experience. In G. D. A. Brown \& N. C. Ellis (Eds.), Handbook of spelling: Theory, process and intervention (pp. 337-363). Chichester, U.K.: Wiley.

PaAP, K. R., \& NoEL, R. W. (1991). Dual-route models of print to sound: Still a good horse race. Psychological Research, 53, 13-24.

Peereman, R., \& Content, A. (1999). LEXOP: A lexical database providing orthography-phonology statistics for French monosyllabic words. Behavior Research Methods, Instruments, \& Computers, $\mathbf{3 1}$, 376-379.

PeEreman, R., Content, A., \& Bonin, P. (1998). Is perception a twoway street? The case of feedback consistency in visual word recognition. Journal of Memory \& Language, 39, 151-174.

Perry, C. (2003). Priming rules of spelling. Quarterly Journal of Experimental Psychology, 56A, 515-530.

Perry, C., \& Ziegler, J. C. (2004). Beyond the two-strategy model of skilled spelling: Effects of consistency, grain size, and orthographic redundancy. Quarterly Journal of Experimental Psychology, 57. 325-356.

Perry, C., Ziegler, J. C., \& Coltheart, M. (2002). A dissociation between orthographic awareness and spelling production. Applied Psycholinguistics, 23, 43-73.

Plaut, D. C., Mc Clelland, J. L., Seidenberg, M. S., \& Patterson, K. (1996). Understanding normal and impaired word reading: Computational principles in quasi-regular domains. Psychological Review, 103, 56-115.

PlaUT, D. C., \& Shallice, T. (1993). Deep dyslexia: A case study of connectionist neuropsychology. Cognitive Neuropsychology, 10 , 377-500.

RAPP, B., EPstein, C., \& TAinturier, M. J. (2002). The integration of information across lexical and sublexical processes in spelling. $C_{\text {og- }}$ nitive Neuropsychology, 19, 1-29.

Rastle, K., \& ColthearT, M. (1999). Serial and strategic effects in reading aloud. Journal of Experimental Psychology: Human Perception \& Performance, 25, 482-503.

Roberts, M. A., Rastle, K., Coltheart, M., \& Besner, D. (2003). When parallel processing in visual word recognition is not enough: New evidence from naming. Psychonomic Bulletin \& Review, $\underline{\mathbf{1 0}}_{2}$ 405-414.

SaNDERS, R. J., \& Caramazza, A. (1990). Operation of the phonemeto-grapheme conversion mechanism in a brain injured patient. Reading \& Writing, 2, 61-82.

SeidenberG, M. S., \& McClelland, J. L. (1989). A distributed, developmental model of word recognition and naming. Psychological Review, 96, 523-568.

SHALLICE, T. (1981). Phonological agraphia and the lexical route in writing. Brain, 104, 413-429.

Strain, E., \& HeRDMAN, C. M. (1999). Imageability effects in word naming: An individual differences analysis. Canadian Journal of Experimental Psychology, 53, 347-359.

Strain, E., Patterson, K. E., \& Seidenberg, M. S. (1995). Semantic effects in single-word naming. Journal of Experimental Psychology: Learning, Memory, \& Cognition, 21, 1140-1154.
Strain, E., Patterson, K. E., \& Seidenberg, M. S. (2002). Theories of word naming interact with spelling-sound consistency. Journal of Experimental Psychology: Learning, Memory, \& Cognition, 28, 207214.

TABossi, P., \& LAGHI, L. (1992). Semantic priming in the pronunciation of words in two writing systems: Italian and English. Memory \& Cognition, 20, 303-313.

TAINTURIER, M. J., \& RAPP, B. (2000). The spelling process. In B. Rapp (Ed.), The handbook of cognitive neuropsychology: What deficits reveal about the human mind (pp. 263-289). Philadelphia: Psychology Press.

TAYLOR, T. E., \& LuPKER, S. J. (2001). Sequential effects in naming: A time-criterion account. Journal of Experimental Psychology: Learning, Memory, \& Cognition, 27, 117-138.

VAN Hell, J. G., \& DE Groot, A. M. B. (1998). Disentangling context availability and concreteness in lexical decision and word translation. Quarterly Journal of Experimental Psychology, 51A, 41-63.

ViTKOVITCH, M., HuMPhreYs, G. W., \& LlOYD-JoNES, T. J. (1993). On naming a giraffe a zebra: Picture naming errors across different categories. Journal of Experimental Psychology: Learning, Memory, \& Cognition, 19,243-259.

WATERS, G. S., \& SEIDENBERG, M. S. (1985). Spelling-sound effects in reading: Time-course and decision criteria. Memory \& Cognition, 13 , 557-572.

Woollams, A. M., \& Kinoshita, S. (1997). Strategic modification of response criterion for initiation of articulation in speeded naming. Paper presented at the 24th Annual Experimental Psychology Conference, Deakin University, Geelong, Victoria, Australia.

Zevin, J. D., \& Balota, D. A. (2000). Priming and attentional control of lexical and sublexical pathways during naming. Journal of Experimental Psychology: Learning, Memory, \& Cognition, 26, 121-135.

ZEVIN, J. D., \& SEIDENBERG, M. S. (2002). Age of acquisition effects in word reading and other tasks. Journal of Memory \& Language, 47 , $1-29$.

ZORZI, M. (2000). Serial processing in reading aloud: No challenge for a parallel model. Journal of Experimental Psychology: Human Perception \& Performance, 26, 847-856.

Zorzi, M., Houghton, G., \& ButTerworth, B. (1998). Two routes or one in reading aloud? A connectionist dual-process model. Journal of Experimental Psychology: Human Perception \& Performance, 24, $1131-1161$.

\section{NOTES}

1. Regarding the rule versus degree of consistency issue in spelling, one difficulty that has often been alluded to is the definition of unambiguous criteria for distinguishing between regularly and irregularly spelled words in languages in which multiple graphemic options are the rule rather than the exception. Given the highly polygraphic nature of spelling in languages such as French and English, it might appear that proposing a nonlexical conversion procedure based upon sound-tospelling correspondence rules would be intolerably unreliable (Barry \& Seymour, 1988). Nevertheless, the polygraphic nature of spelling in French and English does not logically preclude the involvement of a PO conversion procedure that uses rules, as has been proposed for reading aloud (Coltheart \& Rastle, 1994; Rastle \& Coltheart, 1999).

2. Exception words can be defined as words having atypical graphemephoneme correspondences (Roberts, Rastle, Coltheart, \& Besner, 2003).

3. By irregular nonwords, we mean nonwords having at least one phoneme-grapheme correspondence that can be spelled in more than one way. This does not, therefore, mean that participants provide the irregular spelling for the nonwords. 
APPENDIX

List of the Experimental Words Used in the Experiments

\begin{tabular}{|c|c|c|c|}
\hline \multicolumn{2}{|c|}{ Irregular } & \multicolumn{2}{|c|}{ Regular } \\
\hline French & English Translation & French & English Translation \\
\hline clown & clown & cloche & bell \\
\hline bombe & bomb & bouche & mouth \\
\hline dièse & sharp & douche & shower \\
\hline fraise & strawberry & film & film \\
\hline gland & acorn & gourde & water bottle \\
\hline dauphin & dolphin & urne & urn \\
\hline lynx & lynx & louche & soup ladle \\
\hline nœud & knot & niche & kennel \\
\hline plante & plant & poule & hen \\
\hline plat & dish & prune & plum \\
\hline tronc & trunk & tarte & pie \\
\hline $\operatorname{tank}$ & $\operatorname{tank}$ & torche & torch \\
\hline raie & ray & ruche & beehive \\
\hline tasse & cup & tigre & tiger \\
\hline noix & walnut & moto & motorbike \\
\hline loup & wolf & loupe & magnifying glass \\
\hline lampe & lamp & mouche & fly \\
\hline peigne & comb & poche & pocket \\
\hline pull & pullover & plume & feather \\
\hline
\end{tabular}

(Manuscript received April 8, 2003;

revision accepted for publication April 27, 2004.) 